\title{
A IMPORTÂNCIA DA LÍNGUA PORTUGUESA NA MATRIZ CURRICULAR DOS CURSOS SUPERIORES DE SECRETARIADO EXECUTIVO
}

\section{THE RELEVANCE OF THE PORTUGUESE LANGUAGE IN THE HIGHER EDUCATION SECRETARIAL COURSES' CURRICULA}

\section{Katia Cristina de Souza}

Mestrado em Administração pela Universidade Metodista de São Paulo - UMESP, São Paulo (Brasil). Professora do curso de Secretariado Executivo Trilíngue nas Faculdades Metropolitanas Unidas - FMU, São Paulo (Brasil). E-mail: sec.katia@gmail.com

\section{Mariana Sabino Petean Galvão}

Mestranda em Educação, Arte e História da Cultura pela Universidade Presbiteriana Mackenzie - MACKENZIE, São Paulo (Brasil). E-mail: mariana.sabino@gmail.com 


\section{A IMPORTÂNCIA DA LÍNGUA PORTUGUESA NA MATRIZ CURRICULAR DOS CURSOS SUPERIORES DE SECRETARIADO EXECUTIVO}

\section{RESUMO}

O presente estudo tem como objetivo analisar a oferta da disciplina da Língua Portuguesa e correlatas na matriz curricular dos cursos superiores de Secretariado Executivo oferecidos na modalidade bacharelado. Conforme previsto nas Diretrizes Curriculares Nacionais (DCN) preestabelecidas pelo Ministério da Educação, o profissional de Secretariado Executivo deve ter o domínio de, pelo menos, uma língua estrangeira; devendo, igualmente, obter condições de ensino-aprendizagem que propiciem o aprofundamento da língua nacional. Entretanto, o que constatamos nas matrizes curriculares dos cursos oferecidos em âmbito nacional é a ênfase ao ensino de línguas estrangeiras e a redução da carga horária para as disciplinas de Língua Portuguesa e correlatas. Desse modo, aspiramos demonstrar, por meio de pesquisas exploratória e documental, uma análise das matrizes curriculares do curso de Secretariado Executivo em universidades federais e particulares das cinco regiões brasileiras, no intuito de avaliar o impacto que tal ausência pode acarretar no desenvolvimento das competências de comunicação necessárias para a atuação do profissional de Secretariado Executivo na esfera corporativa. Após análise dos resultados, compreendemos que é necessária uma futura reformulação da matriz curricular com o foco na disciplina da Língua Portuguesa e correlatas, no intuito de aprimorar as competências do profissional em relação ao mercado de trabalho.

Palavras-chave: Comunicação. Língua Portuguesa. Matriz Curricular. Secretariado Executivo. 


\title{
THE RELEVANCE OF THE PORTUGUESE LANGUAGE IN THE HIGHER EDUCATION SECRETARIAL COURSES' CURRICULA
}

\begin{abstract}
The objective of the present study is discussing the importance of Portuguese Language in the curricula of the Higher Education Secretarial Courses with bachelor degree. As indicated in the National Curricula Guidelines established by the Education Ministry, the Executive Secretary must have knowledge accuracy in at least one foreign language, besides acquiring teaching-learning conditions that propitiate a deeper knowledge of the national language. However, we note that the national courses' curricula set the focus on the study of the foreign idioms, thus reducing the class hours dedicated to the study of Portuguese Language and its related subjects. Based on that, we developed, via exploratory and documental researches, an analysis of the curricula of the Higher Education Secretarial Courses in Federal and Private Universities in five Brazilian regions, in order to assess the impact that such reduction may cause on the development of the communication skills which are required to perform the Executive Secretary's activities in the corporative environment. After analysing the results, we understood that a future reformulation of the curriculum is necessary, focused on Portuguese Language and correlated subjects, to upgrade the professional's skills in relation to the present labour market requirements.
\end{abstract}

Keywords: Communication. Portuguese Language. Curricula. Executive Secretary. 


\section{INTRODUÇÃO}

Com o passar dos anos o profissional de Secretariado Executivo adaptou-se às mudanças exigidas pelo mercado de trabalho e, além de tornar-se um profissional com poder de gestão, liderança e comunicação na língua materna, necessitou adquirir conhecimento em outros idiomas. $\mathrm{O}$ atual cenário organizacional exige que $\mathrm{o}$ profissional de Secretariado Executivo esteja atento a mudanças e aberto a inovações, detendo, assim, uma visão macro de mercado e uma visão holística da empresa em que atua.

Segundo Bauman (2001), na atualidade, nossa individualidade é exercida com uma autonomia e responsabilidade muito maiores do que há algumas décadas. Esse aspecto é crucial no papel do profissional de Secretariado Executivo e elemento de fundamental importância na condução das negociações, sendo sua carreira a terceira dentre as profissões que mais crescem no país e no mundo, conforme estudos das Organizações das Nações Unidas (ONU), divulgados no site do Guia do Estudante da Editora Abril.

Conforme competências e habilidades descritas no artigo 4, item VI das Diretrizes Curriculares Nacionais (DCN), promulgadas pela Resolução $\mathrm{n}^{\circ}$ 3, de 23 de junho de 2005 (Brasil, 2005a), os profissionais de Secretariado Executivo deverão ter "domínio dos recursos de expressão e de comunicação compatíveis com o exercício profissional, inclusive nos processos de negociação e nas comunicações interpessoais ou intergrupais".

Neiva e D'Elia (2009, p. 30), ao analisarem as novas competências deste profissional, afirmam que "ao atuar como agente facilitador, o profissional de Secretariado Executivo releva o seu desempenho na rede de relações interpessoais que administra. E é nessa rede que imprimirá sua marca". Porém, como ajudá-lo na obtenção e consolidação desse conhecimento?

Estando o trabalho desse profissional interligado à comunicação e ao domínio da linguagem a ser utilizada internamente na organização e com os stakeholders, é de fundamental importância a assertividade na troca de informações do dia a dia da Revista de Gestão e Secretariado-GeSec, São Paulo, v. 7, n. 3, p 47-65, set./dez. 2016. 
empresa em que atua. Segundo Mazulo e Liendo (2010, p. 156) "neste mundo tão competitivo, a assertividade é uma competência emocional cada vez mais exigida no ambiente profissional". E essa assertividade deve ocorrer de forma eficaz na comunicação, na tentativa de evitar ruídos que possam ocasionar conflitos futuros.

Dessa forma, observamos que cabe ao profissional de Secretariado Executivo, desde o início de sua formação, adquirir a competência da comunicação assertiva. Tal competência pode ser trabalhada pela disciplina de Língua Portuguesa ou por meio das disciplinas correlatas, tais como Compreensão de Textos, Leitura e Produção de Textos, Produção Textual, Redação Comercial, Redação Empresarial e Redação Oficial, analisadas neste artigo.

Ao analisarmos as matrizes curriculares ofertadas pelos cursos de Secretariado Executivo no Brasil, observamos a deficiência da manutenção da disciplina da Língua Portuguesa e disciplinas correlatas durante todo o período de formação. A partir dessa análise, pretendemos demonstrar a deficiência na continuidade do estudo da língua-mãe, bem como apresentar uma abordagem de incentivo ao estudante universitário quanto ao conhecimento de sua língua materna e ao entendimento necessário da comunicação na esfera corporativa.

\section{REFERENCIAL TEÓRICO}

\section{Os desafios do profissional do Secretariado Executivo na atualidade}

Dentro do atual mercado de trabalho, o perfil requisitado pelas organizações para os profissionais de Secretariado Executivo, exige a aptidão na manutenção de boas relações de trabalho e convivência com todos os seus colaboradores, dentro e fora do ambiente corporativo. Caberá também a eles a capacidade de agregar valor humano à empresa, reduzindo os índices de conflitos, ao assumirem o papel de facilitadores de relações interpessoais, utilizando da sua resiliência e inteligência emocional a seu favor.

Consoante os argumentos de Medeiros e Hernandes (2010, p. 15),

A secretária também desempenha algumas vezes funções de relações públicas, que compreendem contatos com o público, com o objetivo de influenciá-lo favoravelmente. São preocupações dessa atividade: inspirar, manter simpatia, captar boa vontade, obter

Revista de Gestão e Secretariado -GeSec, São Paulo, v. 7, n. 3, p 47-65, set./dez. 2016. 
confiança, conseguir apreciação, buscar compreensão, esclarecer dúvidas entendimentos, fortalecer o moral.

Nós podemos compreender, portanto, que para esse profissional, a "relação pública" demanda habilidade em se relacionar positivamente com as pessoas com quem trabalha, cientes de que o bom relacionamento interpessoal é fator indispensável para o desempenho corporativo. Contudo, é necessário que o profissional de Secretariado Executivo tenha a compreensão de seu(s) gestor(es) e dos demais colaboradores como indivíduos e não só como profissionais, demonstrando bom senso e confiabilidade no gerenciamento de informações, a fim de que o trabalho seja realizado de maneira harmoniosa.

Com as mudanças ocorridas no mercado de trabalho atualmente, as organizações têm buscado nos profissionais de Secretariado Executivo fortes aliados, capazes de juntos, trilharem os caminhos para o sucesso. Para Nonato Júnior (2009), a carreira desse profissional passou também por mudanças nestas três últimas décadas, reformulando seu aparato técnico, tático e estratégico, a fim de adaptar-se às novas exigências e avanços tecnológicos. A globalização exigiu desse profissional uma postura aberta a mudanças, requerendo a ele a proatividade, flexibilidade, responsabilidade, resiliência, dentre outras aptidões necessárias para a prestação de suporte técnico às diversas camadas hierárquicas, já que, neste novo cenário, é comum o profissional de Secretariado Executivo atender a vários gestores.

Segundo Medeiros e Hernandes (2010, p. 316),

Secretária é uma profissional que assessora o executivo, transmite-lhe informações e executa as tarefas que lhe são confiadas. Ela transformou-se, no mundo moderno dos negócios e nessa era de globalização da economia, em assistente executiva que domina as habilidades requeridas num escritório, demonstra capacidade para assumir responsabilidade sem supervisão direta e tem iniciativa para tomar decisões segundo os objetivos assinalados pela autoridade. Atualmente, o executivo espera dela capacidade para desempenhar funções de assistente administrativa que possam aliviá-lo de trabalhos rotineiros e de alguns especializados.

Em suma, a comunicação é imprescindível para o sucesso corporativo do profissional de Secretariado Executivo, pois ele atua como agente facilitador e transmissor de informações claras e objetivas, evitando ruídos na comunicação que possam interferir em futuras negociações da organização. Para Neiva e D'Elia (2009, p. 89), “A qualidade na comunicação permite-nos construir pontes e erradicar os muros, alicerces como os ruídos e desencontros na comunicação" 
O "fazer entender-se" na comunicação é ponto crucial entre os interlocutores e é necessário que o comunicador esteja capacitado não apenas a transmitir a informação, mas também recebê-la. Para Martins, Genghini e Assis Todorov (2011, p. 11), tal aptidão é provida ao aluno de Secretariado Executivo, por meio de uma formação genérica na qual "[...] o eixo do curso se fixa nas disciplinas que abordam as temáticas dos padrões de comportamento, postura e atitudes".

Compreende-se, portanto, que o papel de agente facilitador e veiculador de informações do profissional de Secretariado Executivo envolve aspectos cognitivos e comportamentais, no qual "compete ao profissional facilitar a comunicação e a implantação de mudanças na empresa" (Martins et al., 2011, p. 14).

Com base nessa premissa, para que o profissional de Secretariado Executivo obtenha êxito em sua comunicação, compartilhando informações que "resultem no entendimento comum da mensagem" (Certo, 2003, pp. 293-294), faz-se necessário um investimento no aprendizado e constante aprimoramento no uso da Língua Portuguesa. Tal aprendizado pode-se dar, principalmente, por meio de oportunidades ofertadas por cursos e disciplinas da graduação aplicadas a esta área de conhecimento.

Entretanto, ao analisarmos as matrizes curriculares dos cursos bacharelado em Secretariado Executivo ofertados pelas regiões brasileiras, observamos a carência da manutenção do estudo da disciplina de Língua Portuguesa e disciplinas correlatas, podendo prejudicar a comunicação assertiva do profissional dentro de uma organização.

\section{A importância do aprendizado contínuo da língua portuguesa no curso de Secretariado Executivo}

No novo cenário de mercado globalizado do século XXI, cabe às organizações um processo de gestão da informação que as fortaleçam em competitividade e qualidade de serviços. De acordo com Lima (2002, p.447), “as organizações necessitam de competências individuais para atingirem seus objetivos" e procuram fazer uso da tecnologia e de novos equipamentos que, somados às aptidões de seus colaboradores, contribuirão para uma gestão eficaz e com qualidade no fluxo de informações. Dessa forma, ao analisarmos as perspectivas de atuação do profissional de Secretariado Executivo, elucidamos com a afirmação de Lima (2002, p. 447): 
A Importância da Língua Portuguesa na Matriz Curricular dos Cursos Superiores de Secretariado Executivo

Reconhecidamente a comunicação tem efeito direto na qualidade do ambiente organizacional, e a Secretária Executiva, em razão de trabalhar com executivos de diferente formação cultural e profissional, pelo fator globalização, assimilou as diversas culturas e com isso buscou o conhecimento dos novos processos tecnológicos comunicacionais, a fim de melhor atender a essas exigências do mercado.

Contudo, esse processo tecnológico deve ser consoante à fluidez da comunicação do idioma, a Língua Portuguesa, e as suas aplicações gramaticais de forma assertiva por parte do profissional de Secretariado Executivo, dadas as diversas situações vivenciadas por ele em seu ambiente de trabalho.

Markus (2012, p. 56) corrobora com o exposto, e faz menção sobre as diversas situações vivenciadas no mercado trabalho, porque "a comunicação integra todos os elementos e funções de uma organização, no meio interno e externo. Estamos falando de um processo relacional entre a sociedade, indivíduo, departamentos, unidades e organizações". Diante dessa afirmação, o profissional de Secretariado Executivo não pode ignorar esses processos relacionais apresentados, até porque eles podem transformar-se em uma barreira, ou um ruído na comunicação, influenciando nos processos gerenciais de uma organização.

$\mathrm{Na}$ comunicação empresarial, cabe, portanto, ao profissional de Secretariado Executivo, o uso adequado das aplicações da linguagem, dentro do contexto exigido, de forma clara e objetiva. Um exemplo que podemos citar aqui é a redação de um texto oficial com o objetivo de convidar uma autoridade governamental para a solenidade de posse do novo presidente de uma companhia, onde também estarão presentes os colaboradores de diversos setores da empresa. Esse ofício se diferencia, quanto à sua redação, do convite dirigido aos colaboradores mencionados, devido às exigências da linguagem culta requerida por um documento oficial.

A dinamicidade oral ou escrita da Língua Portuguesa é apresentada de forma culta ou coloquial, respeitando normas gramaticais e a sua correta aplicação dentro de sua capacidade de mutação. A linguagem culta exige "obediência aos padrões linguísticos, uso de vocabulário variado, eliminação do vulgar, linguagem trabalhada e original" enquanto a linguagem coloquial "foge às formalidades e aos requintes gramaticais" (Medeiros, 1998, p. 40)

Dessa forma, observamos a importância da comunicação clara e eficaz no ambiente corporativo, compreendendo-se que ela deve ser abordada pelos docentes dos cursos de Secretariado Executivo para que haja dedicação especial ao estudo da Língua 
Portuguesa e de suas disciplinas correlatas pelos estudantes durante todo seu curso de formação.

Defendemos, assim, a continuidade de aprendizagem da Língua Portuguesa, sob a óptica de proporcionar ao aluno maior oportunidade de êxito na identificação das especificidades da produção textual, corroborando com a Lei de Diretrizes da Educação Nacional (Brasil, 1996b), sobre a qual comentaremos a seguir, e que dá sustentação à hipótese defendida por este artigo.

\section{Lei de Diretrizes e Base da Educação Nacional (LDB) e Diretrizes Curriculares Nacionais (DCN) para o curso de graduação em Secretariado Eexecutivo.}

O Senado Federal criou a Lei n ${ }^{\circ} 9.394$ de 20 de dezembro de 1996 sobre as Diretrizes e Bases da Educação Nacional (LDB) (Brasil, 1996b), a qual dita as diretrizes e as bases da organização do sistema educacional na Gestão do então Presidente da República Fernando Henrique Cardoso e o Ministro da Educação Paulo Renato Souza.

A LDB (Brasil, 1996b) dita as diretrizes educação básica até a educação superior, sendo de maior relevância neste artigo a lei que menciona as Instituições de Ensino Superior (IES), sendo abordado nos artigos 43 a 57. No artigo 53 (Brasil, 1996b) assegura as IES sobre suas atribuições:

Art. 53․ No exercício de sua autonomia, são asseguradas às universidades, sem prejuízo de outras, as seguintes atribuições:

I - criar, organizar e extinguir, em sua sede, cursos e programas de educação superior previstos nesta Lei, obedecendo às normas gerais da União e, quando for o caso, do respectivo sistema de ensino;

II - fixar os currículos dos seus cursos e programas, observadas as diretrizes gerais pertinentes;

III - estabelecer planos, programas e projetos de pesquisa científica, produção artística e atividades de extensão;

IV - fixar o número de vagas de acordo com a capacidade institucional e as exigências do seu meio;

V - elaborar e reformar os seus estatutos e regimentos em consonância com as normas gerais atinentes;

VI - conferir graus, diplomas e outros títulos;

VII - firmar contratos, acordos e convênios;

VIII - aprovar e executar planos, programas e projetos de investimentos referentes a obras, serviços e aquisições em geral, bem como administrar rendimentos conforme dispositivos institucionais;

Revista de Gestão e Secretariado -GeSec, São Paulo, v. 7, n. 3, p 47-65, set./dez. 2016. 
IX - administrar os rendimentos e deles dispor na forma prevista no ato de constituição, nas leis e nos respectivos estatutos;

$\mathrm{X}$ - receber subvenções, doações, heranças, legados e cooperação financeira resultante de convênios com entidades públicas e privadas.

Conforme mencionado no item II do artigo supracitado (Brasil, 1996a), fica estabelecido que cada IES pode fixar os currículos de seus cursos conforme suas diretrizes gerais, sendo que estes cursos têm de ser regulamentados pelo Conselho Nacional de Educação (CNE) através o Ministério da Educação e Cultura (MEC).

O objetivo deste estudo é analisar as matrizes curriculares dos cursos de bacharelado em Secretariado Executivo, conforme suas Diretrizes Curriculares Nacionais (DCN) definidas na Resolução nº 3, de 23 de junho de 2005 (Brasil, 2005a).

$\mathrm{O}$ artigo $2^{\circ}$ das Diretrizes Curriculares Nacionais do curso de Secretariado Executivo (Brasil, 2005a) aborda o componentes curriculares, competências e habilidades, conteúdos curriculares, duração do curso, entre outras observações sobre a organização do curso de graduação. Mas o inciso $\S 1$ deste artigo discrimina de forma clara o que deve conter o projeto pedagógico e seus elementos estruturais:

$\S 1^{\circ} \mathrm{O}$ projeto pedagógico do curso, além da clara concepção do curso de graduação em Secretariado Executivo com suas peculiaridades, seu currículo pleno e sua operacionalização, abrangerá, sem prejuízo de outros, os seguintes elementos estruturais:

I - objetivos gerais do curso, contextualizados em relação às suas inserções institucional, política, geográfica e social;

II - condições objetivas de oferta e a vocação do curso;

III - cargas horárias das atividades didáticas e da integralização do curso;

IV - formas de realização da interdisciplinaridade;

V - modos de integração entre teoria e prática;

VI - formas de avaliação do ensino e da aprendizagem;

VII - modos da integração entre graduação e pós-graduação, quando houver;

VIII - incentivo à pesquisa, como necessário prolongamento da atividade de ensino e como instrumento para a iniciação científica;

IX - concepção e composição das atividades de estágio curricular supervisionado, suas diferentes formas e condições de realização, observado o respectivo regulamento;

$\mathrm{X}$ - concepção e composição das atividades complementares.

Perante essa análise, os cursos de Secretariado Executivo de abrangência nacional podem montar e adaptar suas matrizes curriculares conforme a Resolução n³/2015 das Diretrizes Curriculares Nacionais (DCN) (Brasil, 2005a).

Entretanto, o artigo $4^{\circ}$ citado em Brasil (2005a) diz que os cursos de Secretariado Executivo fazem algumas exigências, únicas a todos os cursos de graduação quanto à 
formação profissional no que tange as competências e habilidades destes futuros profissionais:

Art. $4^{\circ} \mathrm{O}$ curso de graduação em Secretariado Executivo deve possibilitar a formação profissional que revele, pelo menos, as seguintes competências e habilidades:

I - capacidade de articulação de acordo com os níveis de competências fixadas pelas organizações;

II - visão generalista da organização e das peculiares relações hierárquicas e intersetoriais;

III - exercício de funções gerenciais, com sólido domínio sobre planejamento, organização, controle e direção;

IV - utilização do raciocínio lógico, crítico e analítico, operando com valores e estabelecendo relações formais e causais entre fenômenos e situações organizacionais;

V - habilidade de lidar com modelos inovadores de gestão;

VI - domínio dos recursos de expressão e de comunicação compatíveis com o exercício profissional, inclusive nos processos de negociação e nas comunicações interpessoais ou intergrupais;

VII - receptividade e liderança para o trabalho em equipe, na busca da sinergia;

VIII - adoção de meios alternativos relacionados com a melhoria da qualidade e da produtividade dos serviços, identificando necessidades e equacionando soluções;

IX - gerenciamento de informações, assegurando uniformidade e referencial para diferentes usuários;

$\mathrm{X}$ - gestão e assessoria administrativa com base em objetivos e metas departamentais e empresariais;

XI - capacidade de maximização e otimização dos recursos tecnológicos;

XII - eficaz utilização de técnicas secretariais, com renovadas tecnologias, imprimindo segurança, credibilidade e fidelidade no fluxo de informações; e

XIII - iniciativa, criatividade, determinação, vontade de aprender, abertura às mudanças, consciência das implicações e responsabilidades éticas do seu exercício profissional.

$\mathrm{O}$ artigo $5^{\circ}$, da mesma DCN (Brasil, 2005a), continua com as exigências a todos os cursos de Secretariado Executivo, mas focado nos projetos pedagógicos e sua organização curricular.

Art. $5^{\circ}$ Os cursos de graduação em Secretariado Executivo deverão contemplar, em seus projetos pedagógicos e em sua organização curricular, os seguintes campos interligados de formação:

I - Conteúdos básicos: estudos relacionados com as ciências sociais, com as ciências jurídicas, com as ciências econômicas e com as ciências da comunicação e da informação; II - Conteúdos específicos: estudos das técnicas secretariais, da gestão secretarial, da administração e planejamento estratégico nas organizações públicas e privadas, de organização e métodos, de psicologia empresarial, de ética geral e profissional, além do

Revista de Gestão e Secretariado-GeSec, São Paulo, v. 7, n. 3, p 47-65, set./dez. 2016. 
domínio de, pelo menos, uma língua estrangeira e do aprofundamento da língua nacional;

III - Conteúdos teórico-práticos: laboratórios informatizados, com as diversas interligações em rede, estágio curricular supervisionado e atividades complementares, especialmente a abordagem teórico-prática dos sistemas de comunicação, com ênfase em softwares e aplicativos.

Portanto, para as IES terem seus projetos aprovados e, posteriormente, seus cursos reconhecidos, todas as instituições que se propuserem a ofertar o curso de bacharelado em Secretariado Executivo terão obrigatoriamente de manter a estrutura citada na LDB (Brasil, 1996b) e ficar atentas aos artigos $4^{\circ}$ e $5^{\circ}$ das Diretrizes Curriculares Nacionais do curso de Secretariado Executivo (Brasil, 2005a). Contudo, não há a existência de uma padronização completa e detalhada, conforme verificamos no caso da disciplina Língua Portuguesa, grifada no artigo acima, e nosso objeto de estudo.

Além das Diretrizes Curriculares Nacionais que cada curso apresenta, existem também pareceres e resoluções, estabelecidos pela Câmara de Educação Superior (CNE) e homologados pelo Ministério da Educação, que tratam de assuntos complementares como a carga horária mínima exigida para os cursos. No caso dos cursos de graduação, bacharelados, na modalidade presencial, a Resolução $n^{\circ}$ 2, de 18 de junho de 2007 (Brasil, 2007) institui que os cursos de Secretariado Executivo precisam ter, no mínimo, 2.400 horas.

Portanto, embora disposto no artigo 5, item II da Resolução no 3/2005 (Brasil, 2005a), o projeto pedagógico do curso de Secretariado Executivo deva contemplar o aprofundamento da língua nacional, conforme requerido pelo Ministério da Educação, não apresentar uma descrição mais detalhada sobre o nível de aprofundamento para tal conhecimento, tornando-se objeto do parecer da instituição sobre a carga horária destinada ao estudo da Língua Portuguesa; conforme podemos verificar, a posteriori, na tabela descrita e analisada em nosso estudo.

\section{METODOLOGIA}

Este estudo foi realizado a partir de pesquisa documental e exploratória, por meio de uma pesquisa qualitativa, com levantamento de dados secundários de dez universidades, incluindo universidades federais e particulares das cinco regiões do 
Brasil. A análise foi realizada através da matriz curricular do curso de Secretariado Executivo disponibilizado no site institucional de cada universidade.

Para Gil (2008), a pesquisa documental vale-se de informações por meio de documentos escritos (documentos de arquivos, igrejas, sindicatos, instituições etc.); enquanto que a pesquisa exploratória proporciona maior familiaridade com o tema de estudo, provendo ao pesquisador maior conhecimento sobre o assunto a ser levantado. “A investigação qualitativa emprega diferentes concepções filosóficas; estratégias de investigação; e métodos de coleta, análise e interpretação de dados" (Creswell, 2010, p. 206).

Como fonte de dados da pesquisa documental, foram utilizadas a Lei 7.377, de 30/9/85 e a Lei 9.261, de 10/01/96 (Brasil, 1996a) que dispõe sobre o exercício da profissão de secretário e dá outras providências; a Lei n. 9.394, de 20 de dezembro de 1996, (Brasil, 1996b), que estabelece as Diretrizes e Bases da Educação Nacional; a Resolução n. 2, de 18 de junho de 2007, (Brasil, 2007), que dispõe sobre carga horária mínima e procedimentos relativos à integralização e duração dos cursos de graduação, bacharelados, na modalidade presencial e a Resolução $n^{\circ} 3$, de 23 de junho de 2005, (Brasil, 2005a), que institui as Diretrizes Curriculares Nacionais para o curso de graduação em Secretariado Executivo e dá outras providências

Como fonte de dados da pesquisa exploratória, foram pesquisadas universidades das seguintes regiões do Brasil:

- Norte: Amazonas e Roraima;

- Nordeste: Sergipe e Ceará;

- Centro-oeste: Mato Grosso e Goiás;

- Sudeste: São Paulo e Minas Gerais;

- Sul: Paraná e Rio Grande do Sul.

A amostra foi definida (por conveniência), tendo duas universidades por região geográfica, portanto não probabilística; resultando em uma amostra total de 10 universidades, por meio das quais coletamos o material que forneceu subsídio para a análise de dados de nossa pesquisa.

Desse modo, por meio da pesquisa documental e exploratória, buscamos respostas aos nossos questionamentos, a fim de propor meios que atendam às lacunas apresentadas no assunto em questão.

Revista de Gestão e Secretariado -GeSec, São Paulo, v. 7, n. 3, p 47-65, set./dez. 2016. 


\section{ANÁLISE E DISCUSSÃO DOS RESULTADOS}

Para a tabulação de dados, tomou-se por base a carga horária da disciplina de Língua Portuguesa e suas disciplinas correlatas, tais como Compreensão de Textos, Leitura e Produção de Textos, Produção Textual, Redação Comercial, Redação Empresarial e Redação Oficial nos cursos de bacharelado em Secretariado Executivo.

Conforme análise de dados relacionada às matrizes curriculares de dez universidades do Brasil (Quadro 1, a seguir) verifica-se que a carga horária dada à disciplina de Língua Portuguesa e suas correlatas, é menor do que a dedicada às Línguas Estrangeiras, já que, ao contrário destas, a disciplina de Língua Portuguesa e suas correlatas não se encontram presentes em todos os semestres do curso. Conforme demonstrado no Quadro 1, observa-se que em sete das dez universidades pesquisadas, a disciplina relacionada à língua materna tem uma carga horária inferior às de línguas estrangeiras, com variação entre dois a cinco semestres do curso, para Língua Portuguesa, enquanto que a carga horária atribuída às línguas estrangeiras varia de dois a sete semestres.

Para Sodré (2012, p. 242) "o Brasil não integra nenhuma lista de excelência universitária, e as estatísticas não deixam dúvida: o patamar educacional está qualitativamente aquém do requerido por uma potência regional em crescimento como é o caso brasileiro".

Quadro 1 - Pesquisa: Universidades X Cadeiras de Línguas.

\begin{tabular}{|c|c|c|c|c|c|c|c|c|c|c|c|c|c|c|c|c|c|c|c|c|c|c|c|c|c|}
\hline \multirow{2}{*}{ REGIÕES } & \multirow{2}{*}{ ESTADOS } & \multicolumn{3}{|c|}{$19 \mathrm{Sem}}$. & \multicolumn{2}{|c|}{$20 \mathrm{Sem}}$. & \multicolumn{3}{|c|}{39 Sem. } & \multicolumn{2}{|c|}{$49 \mathrm{Sem}}$. & \multicolumn{3}{|c|}{$59 \mathrm{Sem}}$. & \multicolumn{2}{|c|}{$69 \mathrm{Sem}}$. & \multicolumn{3}{|c|}{79 Sem. } & \multicolumn{3}{|c|}{$89 \mathrm{Sem}}$. & \multicolumn{2}{|c|}{ TOTAL } & \multirow[t]{2}{*}{ TOTAL } \\
\hline & & $\mathrm{LP}$ & 니나 & EL & DI & LE & LP & 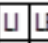 & EL & $P L$ & $L F$ & LP & ㄴ) & $\mathrm{E}$ & $P$ & $11 \mathrm{~B}$ & L & & $L F$ & \begin{tabular}{|l|l|}
$\mathrm{LP}$ \\
\end{tabular} & பاப் & & & LE & \\
\hline $\begin{array}{l}\text { Centro- } \\
\text { oeste }\end{array}$ & Mato Grosso & $x$ & $x \mid x$ & $x$ & $\mathrm{x}$ & $x$ & $x$ & $x \mid x$ & $x$ & $x \mid x$ & $x$ & $x$ & $x$ & $x$ & $\mathrm{x}$ & $x \mid x$ & & & $\ldots$ & $\ldots$ & ... & & 56 & 6 & 18 \\
\hline Sul & RioGrande doSul & $x$ & $x \mid x$ & & $\mathrm{x}$ & $x$ & & $x \mid x$ & $x$ & $x \mid x$ & $x$ & $x$ & $x$ & $\mathrm{x}$ & $x$ & $x \mid x$ & & $x$ & $x$ & $\ldots$ & $\ldots$ & & 5 & 7 & 19 \\
\hline Sudeste & São Paulo & $x$ & $\mathrm{x}$ & $y$ & $x$ & & $x$ & $\mathrm{x} x$ & $x$ & $x \mid x$ & $x$ & $x$ & $\mathrm{x}$ & $\mathrm{x}$ & & $x \mid x$ & 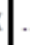 & $\ldots$ & $\ldots$ & $\ldots$ & ... & . & 5 & 4 & 15 \\
\hline $\begin{array}{l}\text { Centro- } \\
\text { oeste }\end{array}$ & Goiás & $\mathrm{x}$ & $\mathrm{x}$ & $x$ & $x$ & & $x$ & $\mathrm{x}$ & ) & $x$ & $x$ & $x$ & & $\mathrm{x}$ & & & . & & $\ldots$ & ... & ... & 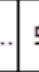 & 5 & 2 & 10 \\
\hline Sudeste & Minas Gerais & $x$ & & $x$ & $\mathrm{x}$ & & $x$ & $x$ & ) & $x \mid x$ & & & $x$ & $x$ & & $x \mid x$ & & $x$ & $x$ & & $x$ & $k$ & 4 & 4 & 15 \\
\hline Norte & Amazonas & $x$ & $\mathrm{x}$ & $x$ & $x$ & & $x$ & $x \mid x$ & $x$ & $x \mid x$ & $x$ & & $x$ & $x$ & & $x \mid x$ & & & $\cdots$ & .. & . & . & 4 & 4 & 14 \\
\hline Norte & Roraima & $x$ & $\mathrm{x}$ & $x$ & $\mathrm{x}$ & & $x$ & $x$ & ) & $x \mid x$ & & & & $\mathrm{x}$ & & $x$ & & & $x$ & & $x$ & $x$ & 4 & 4 & 12 \\
\hline Sul & Paraná & $x$ & $\mathrm{x}$ & $x$ & $\mathrm{x}$ & & & $x$ & ) & $x \mid x$ & & $x$ & $x$ & & & $x$ & . & . & $\cdots$ & $\ldots$ & $\ldots$ & 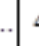 & 4 & 0 & 10 \\
\hline Nordeste & Sergipe & $x$ & & $x$ & $\mathrm{x}$ & & $x$ & $x \mid x$ & $x$ & $x$ & $x$ & & $x$ & & & & & & & & & 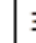 & 3 & 2 & 9 \\
\hline Nordeste & Ceará & $x$ & & $x$ & & & & $x$ & & $x$ & & & $x \mid$ & & & $\mathrm{x}$ & & $\mathrm{x}$ & & & & & 2 & 0 & 7 \\
\hline
\end{tabular}

Fonte: Pesquisa exploratória dos autores.

Revista de Gestão e Secretariado-GeSec, São Paulo, v. 7, n. 3, p 47-65, set./dez. 2016. 
Nessa mesma análise de dados, observamos, igualmente, que somente duas das dez universidades pesquisadas destinam à sua matriz curricular a mesma carga horária para a disciplina de Língua Portuguesa e suas correlatas, e Línguas Estrangeiras (quatro e seis semestres), enquanto que apenas uma universidade destina carga horária superior para a disciplina de Língua Portuguesa $(\mathrm{LP}=$ cinco semestres; $\mathrm{LI}=$ três semestres; $\mathrm{LE}=$ dois semestres).

Outro ponto importante apreendido por meio dessa análise, demonstra que as regiões Sul, Sudeste e Centro-oeste, regiões com melhores índices de Índice de Desenvolvimento Humano Municipal (IDHM ) do Brasil, destinam uma carga horária maior ao estudo da Língua Portuguesa e disciplinas correlatas (de quatro a seis semestres do curso), enquanto que as regiões Norte e Nordeste, os mais baixos índices de IDHM do Brasil, atribuem à sua matriz curricular carga horária inferior para tal disciplina (dois a quatro semestres);

Para tanto, fez-se necessário analisar mais a fundo o currículo dessas disciplinas; em que "O currículo costuma refletir um projeto educativo globalizado, que agrupa diversas facetas da cultura, do desenvolvimento pessoal e social, das necessidades vitais dos indivíduos para seu desempenho em sociedade, aptidões e habilidades consideradas fundamentais etc.” (Sacristán, 2000, p. 55). Ainda assim, nota-se que a cultura, o desenvolvimento social e a globalização podem refletir de forma diferenciada em cada região estudada.

Cientes de que o IDHM é constituído da avaliação de critérios relacionados à saúde, educação e renda, concordamos com os argumentos de Maffesoli (2010) que até mesmo os produtos ditos globais têm de satisfazer a idiossincrasia de cada tribo, apresentando aspectos mínimos de homogeneidade específica para cada região. "Pósmodernidade: sinergia entre o arcaico e o desenvolvimento tecnológico" (Maffesoli, 2010, p. 40).

E para atender a idiossincrasia de cada região estudada, as IES que ofertam os cursos de bacharelado em Secretariado Executivo devem atentar-se a LDB (Brasil, 1996b) e a DCN (Brasil, 2005ª), apresentadas no capítulo 3, preestabelecidas pelo MEC para "construir currículos que atendam a esse mínimo estabelecido, flexibilizando, por meio de uma organização curricular, temas que atendam às exigências do mercado de trabalho [...]" (Mota \& Magalhães, 2013, p. 16).

Revista de Gestão e Secretariado-GeSec, São Paulo, v. 7, n. 3, p 47-65, set./dez. 2016. 
Em regiões mais industrializadas, com a presença de multinacionais, observamos que as regiões Sul e Sudeste privilegiam as línguas estrangeiras em suas matrizes curriculares, adaptando-se às exigências do mercado de trabalho. A disciplina de Língua Inglesa e suas correlatas tem em nove das dez universidades estudadas sua carga horária distribuída na maior parte do curso, variando entre três a sete semestres; apresentando em sete das dez matrizes analisadas, com a carga horária superior a destinada à disciplina de Língua Espanhola.

Consoante Santos (2005), a Língua Inglesa teve sua inserção no Brasil devido ao poderio econômico e militar dos Estados Unidos, ocorrido após a Segunda Guerra Mundial. E na década de 1960, tem sua aprendizagem expandida por meio de acordos de cooperação entre os dois países e mediante a necessidade do ensino de inglês a países periféricos.

Em relação à inserção da Língua Espanhola no Brasil, Bissaco e Reatto (2007) argumentam que, em 1956, o então presidente Juscelino Kubitschek requisitou ao Congresso Nacional que fosse elaborado um projeto de lei que incluísse o Espanhol na matriz curricular do ensino brasileiro. Porém, tal projeto não foi aprovado, devido a interferências político-culturais da Inglaterra e França com o Brasil. Somente em 5 de agosto de 2005 foi decretada a Lei $n^{\circ} 11.161$ (Brasil, 2005b), tornando obrigatória a oferta da Língua Espanhola nas matrizes curriculares do ensino médio.

Diante do exposto, com a vinda das multinacionais para o contexto corporativo brasileiro, as línguas inglesa e espanhola tornam-se de suma importância para o mercado brasileiro, demandando do profissional de Secretariado Executivo o conhecimento de língua estrangeira para a efetivação de negociações, e consequente ascensão a cargos de gestão dentro das organizações. Desse modo, por este estar ligado diretamente com a gestão, exigiu-se, do profissional de Secretariado Executivo a competência em outra(s) língua(s) para o desenvolvimento das tarefas pertinentes ao cargo.

Não obstante a necessidade de estudo de idiomas estrangeiros advinda desse novo cenário corporativo, defendemos, por motivos aqui já comentados, a importância do estudo e constante aprofundamento no conhecimento da Língua Portuguesa e disciplinas correlatas como base para o desenvolvimento do profissional de Secretariado Executivo.

Dessa forma, os dados de nossa pesquisa tornam-se relevantes ao demonstrarem que, ao destinar uma carga horária superior ao aprimoramento do profissional em língua Revista de Gestão e Secretariado-GeSec, São Paulo, v. 7, n. 3, p 47-65, set./dez. 2016. 
estrangeira, as matrizes curriculares dos cursos pesquisados de Secretariado Executivo no Brasil podem apresentar uma defasagem dos alunos com relação ao aprendizado da língua materna, caso não haja complementariedade desse estudo por meio de outras fontes de aprendizado. E uma defasagem de aprendizado ao longo de sua formação pode também propiciar ao profissional uma falta de conhecimento na forma de comunicar-se assertivamente, tanto na parte oral como escrita, com o público interno das organizações, bem como com os stakeholders.

\section{CONSIDERAÇÕES FINAIS}

Diante das limitações, nosso trabalho não é considerado como conclusivo, uma vez que há a necessidade de uma pesquisa mais abrangente por meio da qual se poderão discutir, com mais detalhamento, possíveis propostas para o aumento da carga horária da disciplina de Língua Portuguesa e das disciplinas correlatas nas matrizes dos cursos superiores de Secretariado Executivo no Brasil.

Outro estudo que deve ser feito é uma análise minuciosa da organização curricular dos cursos bacharéis de Secretariado Executivo, com o foco nas disciplinas de Língua Portuguesa e suas correlatas para saber se atendem os requisitos básicos do seu ensino. Requisitos provindos da aprendizagem da língua materna, trabalhados a fim de formar um profissional com as competências exigidas pelo mercado de trabalho, como por exemplo, a comunicação assertiva e a escrita impecável.

Compreendemos, portanto, que, ao prover suporte para que o estudante tenha entendimento de sua comunicação, o docente promoverá, igualmente, sua compreensão com relação ao papel que desempenha como assessor executivo. Torna-se, assim, relevante o aprofundando dos estudos com relação à Língua Portuguesa, bem como o aprimoramento de sua comunicação e consequente desenvolvimento profissional; uma vez que é por meio da comunicação que nos ligamos ou distanciamos uns dos outros, construindo ou restringindo nossas oportunidades pessoais e profissionais.

Revista de Gestão e Secretariado-GeSec, São Paulo, v. 7, n. 3, p 47-65, set./dez. 2016. 


\section{REFERÊNCIAS}

Bauman, Z. (2001). Modernidade líquida. Rio de Janeiro: Zahar.

Bissaco, C. M. \& Reatto, D. (2007). O ensino como língua estrangeira: uma discussão sócio-política e educacional. Revista Eletrônica de Divulgação Científica em Língua Portuguesa, Linguística e Literatura, Ano 4, n. 7.

Brasil (1996a). Lei no 9.261, de 10 de janeiro de 1996. Dispõe sobre o exercício da profissão de Secretário e dá outras providências e altera a redação dos incisos I e II do art. $2^{\circ}$, o caput do art. $3^{\circ}$, o inciso VI do art. $4^{\circ}$ e o parágrafo único do art. $6^{\circ}$ da Lei $\mathrm{n}^{\circ}$ 7.377, de 30 de setembro de 1985. Brasília, DF: Senado. Recuperado em 11 de outubro, 2015, de http://www.planalto.gov.br/ccivil_03/leis/L9261.htm.

Brasil (1996b). Lei no. 9.394, de 20 de dezembro de 1996. Estabelece as Diretrizes e Bases da Educação Nacional. Brasília, DF: Ministério da Educação e Cultura. $\begin{array}{llllll}\text { Recuperado em } & 11 \text { de }\end{array}$ <http://portal.mec.gov.br/arquivos/pdf/ldb.pdf>.

Brasil (2005a). Resolução $\mathrm{n}^{\circ}$ 3, de 23 de junho de 2005. Institui as Diretrizes Curriculares Nacionais para o curso de graduação em Secretariado Executivo e dá outras providências. Brasília: DF, Ministério da Educação. Recuperado em 10 de outubro, 2015, de <http://portal.mec.gov.br/cne/arquivos/pdf/rces003_05.pdf>.

Brasil (2005b). Lei $\mathrm{n}^{\circ} .11 .161$, de 5 de agosto de 2005. (2005). Dispõe sobre o ensino da língua espanhola. Brasília, DF: Senado. Recuperado em 12 de outubro, 2015, de <http://www.planalto.gov.br/ccivil_03/_Ato2004-2006/2005/Lei/L11161.htm>.

Brasil (2007). Resolução no 2, de 18 de junho de 2007. Dispõe sobre carga horária mínima e procedimentos relativos à integralização e duração dos cursos de graduação, bacharelados, na modalidade presencial. Brasília: DF, Ministério da Educação. Recuperado em 11 de outubro, 2015 de $<$ http://portal.mec.gov.br/index.php?option=com_docman\&view=download\&alias $=168$ 72-res-cne-ces-002-18062007\&category_slug=janeiro-2015-pdf\&Itemid=30192> .

Certo, S. C. (2003). Administração moderna (9a ed.). São Paulo: Prentice Hall.

Creswell, J.W. (2010). Projeto de pesquisa: métodos qualitativos, quantitativos e misto (3a ed.). Porto Alegre: Artmed.

Gil, A. C. (2008). Como elaborar projetos de pesquisa (4a ed.). São Paulo: Atlas.

Guia do estudante. Recuperado em 10 de março, 2016, de $<$ http://guiadoestudante.abril.com.br/profissoes/comunicacao-informacao/secretariadoexecutivo-secretariado-687422.shtml $>$.

IDHM - definição. Recuperado em 11 de outubro, 2015, de $<$ http://www.ebc.com.br/cidadania/2013/07/ranking-mostra-o-idh-de-todos-osmunicipios-do-brasil $>$. 
Lima, S. F. (2002). Tendências do mercado: profissão Secretariado Executivo. In Carvalho, A. P. e Grisson, D. (orgs.). Manual do Secretariado Executivo (5a ed. rev.e atual). São Paulo: D’Livros Editora, pp. 447-456.

Maffesoli, M. (2010). Saturação. São Paulo: Iluminuras.

Markus, K. (2012). O futuro quatro horas atrás - comunicação ecosófica nas organizações. In Galindo, D. (org.). Comunicação institucional \& mercadológica: expansões conceituais e imbricações temáticas. São Bernardo do Campo: Universidade Metodista de São Paulo, pp. 31-67.

Martins, C. B.; Genghini, A. L \& Assis Todorov, M. C. (2011). A resiliência na atuação profissional em Secretariado Executivo. Revista do Secretariado Executivo, Passo Fundo: n.7, pp.9-20.

Mazulo, R. \& Liendo, S. (2010). Secretária: rotina gerencial, habilidades comportamentais e plano de carreira. São Paulo: Editora Senac São Paulo.

Medeiros, J. B. \& Hernandes, S. (2010). Manual da secretária: técnicas de trabalho (12a. ed.). São Paulo: Atlas.

Medeiros, J. B. (1998). Redação empresarial (3a ed.). São Paulo: Atlas.

Mota, A. \& Magalhães, V. (2013). O “invejável currículo" dos projetos pedagógicos.

Neiva, E. Garcia \& D'Elia, M. E. S. (2009). As novas competências do profissional de Secretariado Executivo (2a ed.). São Paulo: IOB.

Nonato Júnior, R. (2009). Epistemologia e teoria do conhecimento em Secretariado Executivo: a fundação das ciências da assessoria. Fortaleza: Expressão Gráfica.

Sacristán, J. G. (2000). O currículo: uma reflexão sobre a prática (3a ed.). Porto Alegre: ArtMed.

Santos, E. F. (2005). O ensino superior no Brasil e os acordos MEC/USAID: o intervencionismo norte-americano na educação brasileira. Recuperado em $1^{\circ}$ de novembro, 2014, de $<$ http://www.dominiopublico.gov.br/pesquisa/DetalheObraForm.do?select_action=\&co _obra $=46254>$.

Sodré, M. (2012). Reinventando a educação: diversidade, descolonização e redes (2a ed.). Petrópolis, RJ: Vozes. 